DIE MELANCHOLIE

DER LITERATUR 


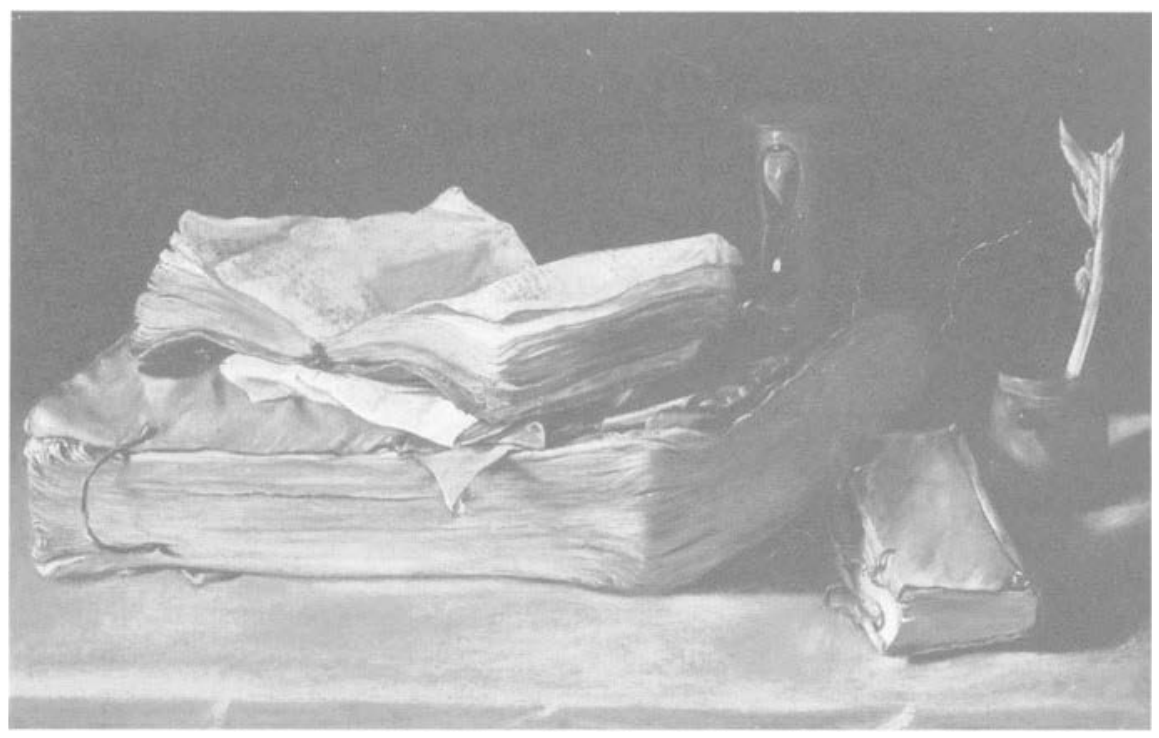

Bücherstilleben

(spanisch, 1. Drittel 17. Jhdt.; Leinwand, 34,5 ×55,3 cm; Kat. Nr. 1667

Gemäldegalerie Berlin, Staatliche Museen Preussischer Kulturbesitz) 
Martina Wagner-Egelhaaf

\section{DIE MELANCHOLIE DER LITERATUR}

Diskursgeschichte und Textfiguration 
Die Deutsche Bibliothek - CIP-Einheitsaufnahme

\section{Wagner-Egelhaaf, Martina:}

Die Melancholie der Literatur : Diskursgeschichte und

Textfiguration / Martina Wagner-Egelhaaf. - Stuttgart ; Weimar :

Metzler, 1997

Zugl.: Habil.-Schr.

ISBN 978-3-476-01533-4

ISBN 978-3-476-01533-4

ISBN 978-3-476-03696-4 (eBook)

DOI 10.1007/978-3-476-03696-4

Dieses Werk einschließlich aller seiner Teile ist urheberrechtlich geschützt. Jede Verwertung außerhalb der engen Grenzen des Urheberrechtsgesetzes ist ohne Zustimmung des Verlages unzulässig und strafbar. Das gilt insbesondere für Vervielfältigungen, Übersetzungen, Mikroverfilmungen und die Einspeicherung und Verarbeitung in elektronischen Systemen.

(C) 1997 Springer-Verlag GmbH Deutschland

Ursprünglich erschienen bei J. B. Metzlersche Verlagsbuchhandlung

und Carl Ernst Poeschel Verlag GmbH in Stuttgart 1997 


\section{Inhalt}

Einleitung

\section{ERster TeIL \\ Der Diskurs der Melancholie 31}

1 Der antike Prä-Text der Melancholie $\ldots \ldots \ldots \ldots \ldots \ldots \ldots \ldots . . \ldots \ldots$

2 Magi und Litterati: Die Melancholie der Gelehrten. Marsilio Ficino . . . 42

3 Das »Bild der Bilder «: Dürers Melencolia I (1524) . . . . . . . . . . . . 62

4 Die Melancholie des Stillebens ...................... $\quad 79$

5 Exzentrik der Melancholie. Robert Burtons Anatomy of Melancholy (1621) . 93

6 Die Zeichen der Melancholie und das Licht der Vernunft . . . . . . . . . 137

7 Das verlorene Objekt. Psychoanalytische Lektüren der Melancholie .... 159

8 Der melancholische Blick. Zu Walter Benjamins Ursprung des deutschen Trauerspiels (1928) . . . . . . . . . . . . . . . . . . . . . . . . 175

9 Resümee und Ausblick: Umriß einer Poetik der Melancholie . . . . . . 196

Zweiter TeIL Literarische Analysen 253

I Johann Gottfried Schnabel. Die Melancholie des Erzählens . . . . . . . 254

1 Die melancholische Insel. Wunderliche Fata einiger See-Fahrer [. . . ]

(1731-1743) ................................

a) Wer ist Eberhard Julius? Zur Konfiguralität eines melancholischen Text-Subjekts . . . . . . . . . . . . . . . . . . . 263

b) Utopie und Melancholie . . . . . . . . . . . . . . . . . . . 273

c) Von der Mündlichkeit zur Schriftlichkeit . . . . . . . . . 286

d) Melancholische Autorschaft . . . . . . . . . . . . . . . . . . . . . . 292

e) Felsenburg-Lektüren $\ldots \ldots \ldots \ldots \ldots \ldots \ldots \ldots \ldots \ldots \ldots$

2 Galanterie und melancholisches Spiel. Der im Irr-Garten der Liebe herum taumelnde Cavalier [. . . (1738) . . . . . . . . . . . . . . . . . . . . . . 307

3 „In literis«. Der Sieg des Glücks und der Liebe über die Melancholie [. . .] (1748) 321

II Karl Philipp Moritz. Die Melancholie des Lesens . . . . . . . . . . 326

1 Schwarze Bilder. Das Magazin zur Erfahrungsseelenkunde (1783-1793) . . 329

2 Die Unlesbarkeit der Zeichen. Anton Reiser (1785-1790) . . . . . . . . 349

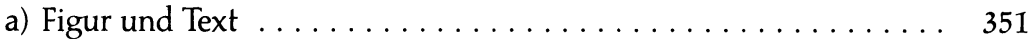

b) Der Melancholiker als Leser . . . . . . . . . . . . . . . . 356

c) Das Theater der Stimme . . . . . . . . . . . . . . . . . . . . 365

d) Die Leiden der Poesie . . . . . . . . . . . . . . . . . . 370

e) Labyrinthe .............................. 377

3 Eine Geometrie der Melancholie. Moritz' Schriften zur Ästhetik . . . 384 
III Gottfried Keller. Die Melancholie des Bildes . . . . . . . . . . . . . 407

1 Das Bild der Melancholie. Kellers Melancholie-Gedicht (1851/83) _ . . 411

2 Still-Leben oder Nature morte. Der grüne Heinrich $(1854 / 55 ; 1879 / 80) \quad$. 416

a) Das dilettantische Bild . . . . . . . . . . . . . . . . . . . . 421

b) Das Bild als Schauplatz ...................... 430

c) Der Schauplatz der Bilder . . . . . . . . . . . . . . . . . 444

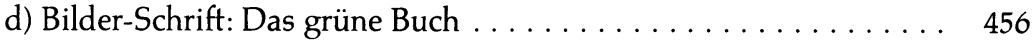

3 Schmollkunst und Pfuschwerk. Melancholikerfiguren in Die Leute von Seldwyla $(1856 ;$ 1874) . . . . . . . . . . . . . . . . . . . . . . . . 474

a) Pankraz, der Schmoller ......................... 480

b) Kleider machen Leute ........................... . 487

Schluß . . . . . . . . . . . . . . . . . . . . . . . . 528

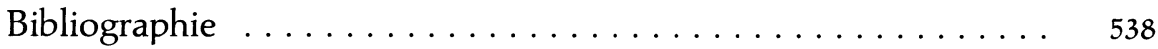

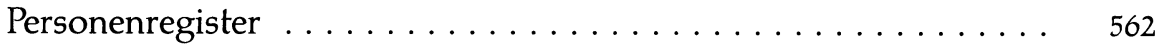

